\title{
A Practice of Useing Remote Sensing Technologies in Geoecological Studies
}

\author{
Shushanik G. Asmaryan*, Vahagn S. Muradyan, \\ Garegin O. Tepanosyan, Azatuhi Hovsepyan, \\ Lilit Minasyan and Armen K. Saghatelyan \\ Center for Ecological-Noosphere Studies NAS RA \\ 68 Abovyan, Yerevan, 0025, Armenia
}

Received 12.05.2015, received in revised form 16.07.2015, accepted 20.09.2015

The main areas of the use of remote sensing technologies in Armenia are considered in the article. The basic scientific-technological resources for their perspective development are also discussed. The later will serve a background for the development of remote sensing methods and monitoring system in the future.

Keywords: Remote sensing, environmental state, spectral signatures, monitoring system.

DOI: $10.17516 / 1999-494 X-2015-8-8-1024-1031$.

\section{Практика применения дистанционных технологий в геоэкологических исследованиях}

Ш.Г. Асмарян, В.С. Мурадян, Г.О. Тепаносян, А. Овсепян, Л. Минасян, А.К. Сагателян Центр эколого-ноосферных исследований НАН Республики Армения Армения, 0025, Ереван, Абовяна, 68

Рассматриваются основные направления применения дистаниионных технологий 6 Республике Армения. Изложены базовые научно-технологические ресурсы для развития перспективных направлений, которые обеспечат надежную научно-методическую основу для совершенствования и разработки дистанционных методов и создания на этой основе мониторинговой системы.

Ключевые слова: дистанционное зондирование, состояние окружающей среды, дешифровочные признаки, мониторинговая система.

(C) Siberian Federal University. All rights reserved

* Corresponding author E-mail address: ashuk@list.ru 
Технологии дистанционного зондирования земли (Д33) в силу своих уникальных особенностей (широкий территориальный охват, оперативность, контроль за отдаленными районами и т. д.) имеют важное значение для контроля и мониторинга в разных сферах социальноэкономической деятельности и в работах по оценке антропогенного и техногенного воздействия на окружающую среду [9]. Экосистемы, отраженные на многозональных космических снимках, представляют собой совокупность объектов, отличающихся по цвету и яркости, что позволяет использовать ДДЗ для изучения их антропогенной трансформации [10].

В Центре эколого-ноосферных исследований Национальной академии наук Республики Армения (ЦЭНИ) применение технологий ДЗ в экологических исследованиях началось с 80-х гг. прошлого века и, как показывает практика, охватывает довольно широкий спектр проблем. На основе сопоставления спутниковых и наземных данных выполнены и ведутся разработки дистанционных методов в направлении:

- оценки и выявления динамики изменения ландшафтов;

- аэрокосмического мониторинга экологического состояния растительности (контаминация, запыление);

- оценки состояния современного землепользования и рациональности функционального зонирования территорий для решения задач территориального планирования;

- оценки степени эродированности высокогорных пастбищ;

- оценки продуктивности пастбищ и сенокосов;

- оценки риска отдельных промышленных объектов;

- моделирования аварийных ситуаций на АЭС.

Дистанционные методы оценки динамики изменения ландшафтов основаны на анализе спектральных кривых и вегетационных индексов. В частности, вегетационный индекс NDVI (Normalized Difference Vegetation Index) - простой показатель количества фотосинтетически активной биомассы, один из самых распространенных и используемых индексов для количественной оценки экосистем [12].

На примере Сюникского марза в южной части Армении методом классификации объектов с обучением (Supervised classification) и с помощью вегетационных индексов выделены классы и проведен анализ спектральных кривых, которые характеризуют отражательную способность объектов в разных зонах спектра и являются одними из важнейших дешифровочных признаков природных и антропогенных объектов [6,8]. В результате выявлена пространственновременная динамика изменения ландшафтов в данном регионе за период 1976-2006 гг. (рис. 1).

В последние годы в аспекте дистанционного зондирования спектральные характеристики растительности изучались многими рабочими группами как в лабораториях, так и на природных полигонах $[6,8-9,11]$. Для разработки методов дистанционного мониторинга экологического состояния города Еревана по результатам биогеохимических исследований проведена спектрофотометрическая съемка для выявления особенностей спектральной отражательной способности листьев деревьев отдельных видов (ясень обыкновенный, вяз мелколистный). На выбранных модельных территориях исследованы листья деревьев в зонах с различной степенью загрязнения [3]. Сопоставление данных биогеохимических исследований со спектральными данными, выраженными на многозональном космическом снимке WorldView2, а также сравнение кривых спектрального отражения листьев деревьев данного вида с суммарным ко- 
эффициентом загрязнения тяжелыми металлами (ТМ) позволили выявить обратную корреляционную связь между коэффициентами загрязнения и значениями спектрального отражения в ближнем инфракрасном диапазоне электромагнитного спектра (рис. 2).

1976 r.
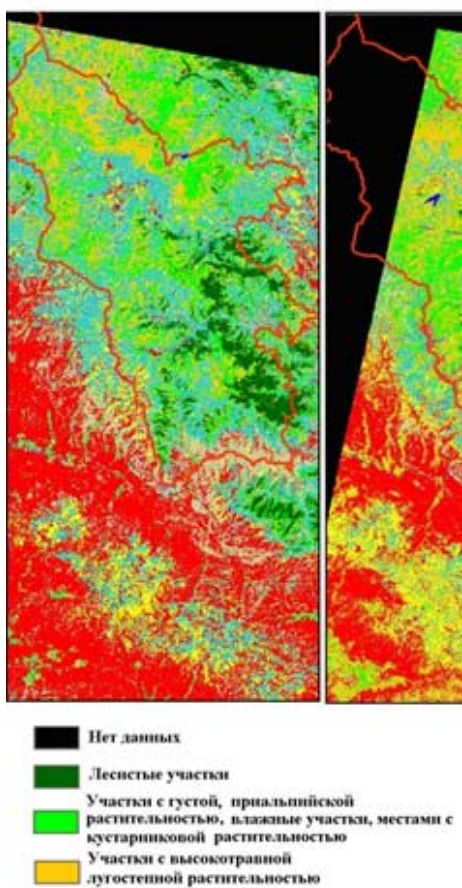

$1987 \mathrm{r}$

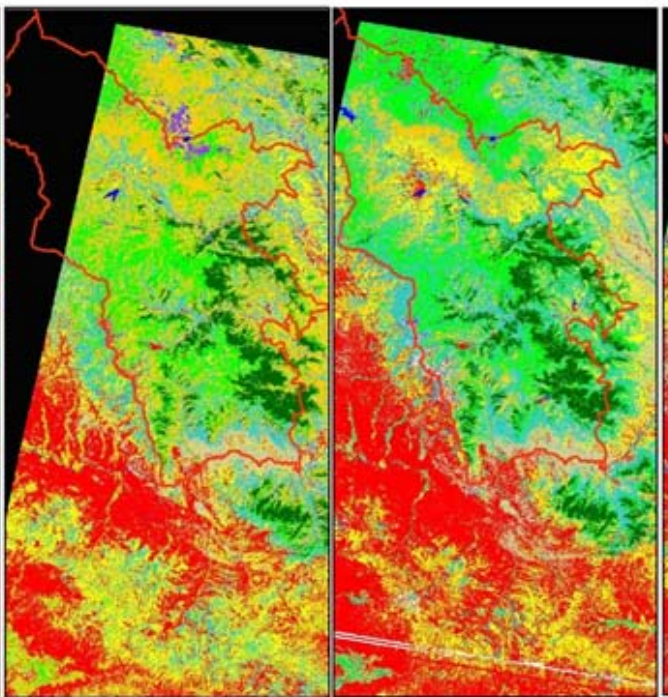

УС.ТОВНЫЕ. ОБОЗНАЧЕННЯ

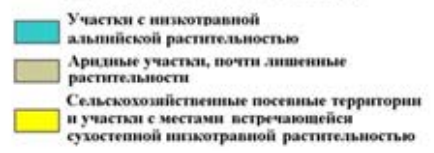

$2006 \mathrm{r}$.
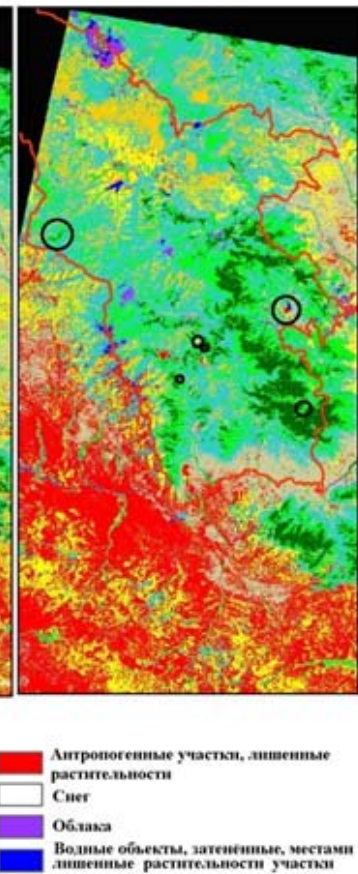

Рис. 1. Динамика изменения ландшафтов Сюникского марза по методу классификации с обучением многоспектральных космических снимков

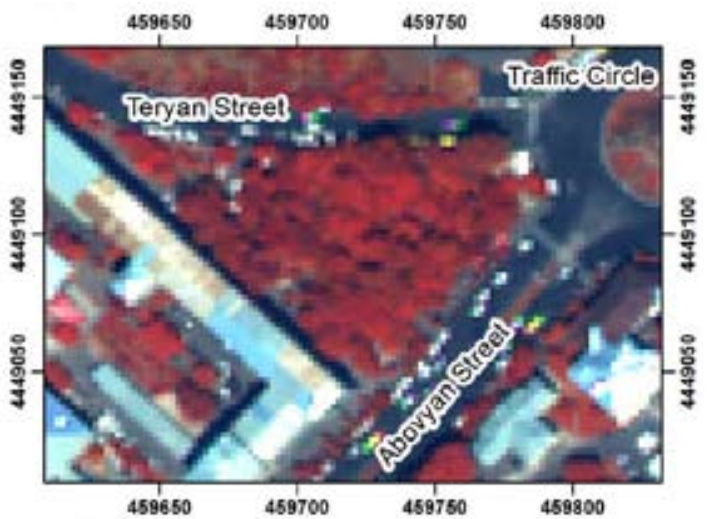

a

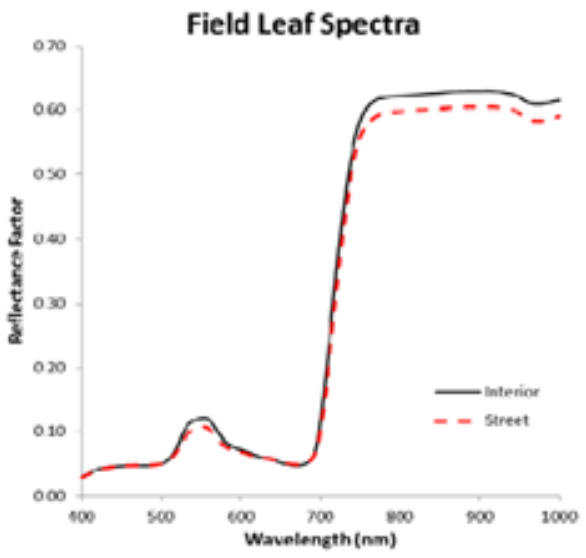

б

Рис. 2. а) многозональный космический снимок WorldView2 модельной территории, б) спектральные кривые значений листьев деревьев, отражающие разницу спектральных значений в зеленом, красном и инфракрасном диапазонах 
Функциональное зонирование территории города проводилось путем дешифрирования объектов землепользования по космическим снимкам QuickBird по классификации CORINE (Coordination of Information on the Environment).

Целесообразность применения номенклатуры землепользования CORINE обусловлена рядом ее свойств, прежде всего относительной простотой, универсальностью, применимостью к задачам ландшафтоведения и, что немаловажно, возможностью распознавания тех или иных категорий земель по данным дистанционного зондирования [4, 5].

Программа «Координация информации по окружающей среде» (Coordination of Information on the Environment-CORINE) была учреждена Еврокомиссией для создания согласованной географической информационной системы о состоянии окружающей среды в странах ЕС. Номенклатура земной поверхности CORINE была разработана для того, чтобы систематизировать и упорядочить информацию о разнообразии почвенно-растительного покрова территории ЕС [17]. Легенда земной поверхности CORINE 3-го уровня состоит из 44 классов с минимальной единицей картографирования 25 га в масштабе 1:100 000 [13]. В 1998 г. номенклатура земной поверхности CORINE была расширена Объединенным исследовательским центром EC JRC (Joint Research Centre) для проекта MURBANDY4 - предшественника проекта MOLAND [14, 17]. В результате минимальная единица картографирования сократилась с 25 до 1 га для городских и 3 га для сельских районов. Разработана более детальная схема 4-го уровня, которая включает более 80 классов в масштабе 1:25 000 [13, 14].

Ереван - столица Армении - находится в северо-восточной части Араратской долины, занимая площадь 223 кв. км. Это крупнейший экономический центр республики. По данным переписи населения на 2011 г., общее количество населения города составляет 1.1060138 человек, он включает 12 муниципальных общин, где сконцентрирована одна треть всего населения республики [1].

За последние десятилетия территория Еревана интенсивно меняет свой облик. Мониторинг состояния городской среды требует внедрения и использования международного опыта и технологий. Принятые в Армении кадастровые описания не совпадают с классификатором CORINE и вовсе не ориентированы на оценку текущего и динамического состояния земель. Поэтому распознавание соответствующих классов земель по материалам спутниковых съемок является самостоятельной задачей с целым рядом возможных фундаментальных и практических приложений. Более того, для использования модели оценки экологического состояния и прогноза развития городских территорий в качестве входных данных, например модели MOLAND, требуется тематический слой земельного покрова / землепользования CORINE территории Еревана. Сделана попытка создания нового тематического слоя землепользования территории города на основе номенклатуры CORINE $[1,6]$.

Дистанционное зондирование и ГИС-технологии использовались в качестве инструмента для создания тематических слоев. Информационное обеспечение работы составили многозональный космический снимок QuickBird (рис. 3), кадастровая карта землепользования Еревана, генплан города, карта функционального зонирования Еревана 2001 г. в масштабе 1: 4500 (ООО «Коллаж»), картографические слои OpenStreetMap (OSM).

Так как космический снимок не полностью покрывал всю территорию города и, в частности, его юго-восточные и северные части, в качестве картографической основы были использо- 


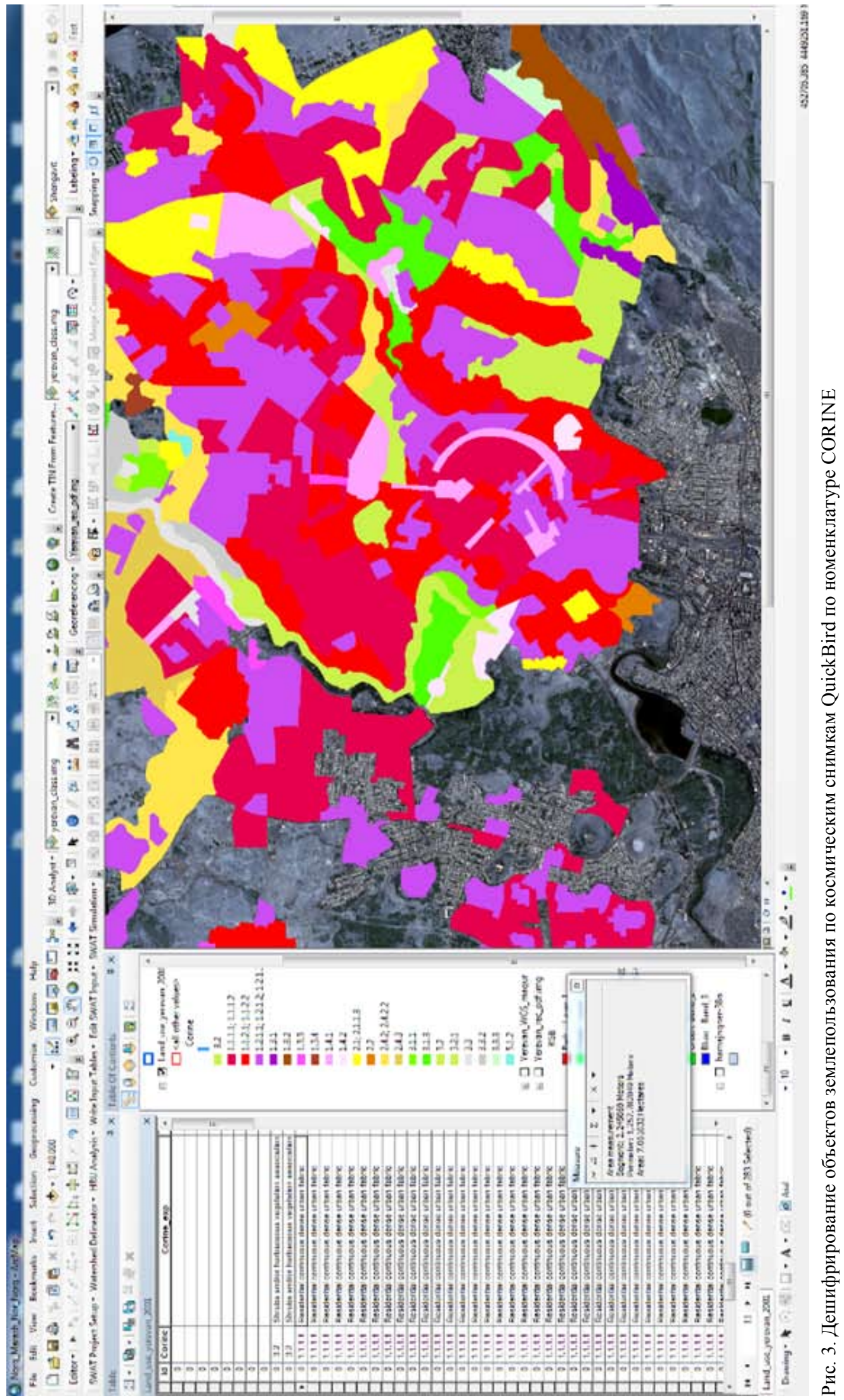


ваны космические снимки 2011 г., полученные и скачанные с помощью программы ArcGis 10.1 Basemap и SAS planet (Release: 121010). В этих частях города пространственные объекты 2002 г. были восстановлены с использованием инструмента Google Earth «TimeSlider».

Первоначально разделялись два вида жилых кварталов: непрерывные и прерывистые. В номенклатуре 4-го уровня они были разделены на плотные, средней плотности и неплотные классы [14], которые отличаются друг от друга процентным соотношением естественных и искусственных поверхностей и числом этажей в жилых зданиях $[16,15]$. Для определения этих классов осуществлена контролируемая классификация (Supervised Classification) космического снимка QuickBird в программной среде ERDAS Imagine 2014 и рассчитано процентное соотношение четырех полученных классов: водные объекты, растительность, почвенный покров и здания для каждой жилой площади по отдельности (ArcGis 10.1 Zonal Statistic tool).

В результате был получен тематический слой землепользования CORINE г. Еревана на 2002 г., который обновлен для установления тематических слоев на 2011 г. с помощью OpenStreetMaр и Google Earth (рис.4).

Для последующей корректировки полученных результатов требуются дополнительные соответствующие данные (космические снимки и данные по землепользованию). После корректировки планируется использование полученных слоев для запуска оценочных и прогнозных моделей экологического состояния городской среды.

Для эффективного контроля и управления высокогорными пастбищами необходима система мониторинга, неотъемлемым компонентом которой являются ГИС- и дистанционные технологии с их мощным программно-аппаратным потенциалом. Неумеренное использование легко досягаемых пастбищ в Армении привело к потере их продуктивности с серьезными экологическими и экономическими последствиями. Кроме того, в неполном объеме используется основная часть сенокосов, которые являются основным источником высококачественного корма. В ЦЭНИ разработана методика оценки экологического состояния высокогорных пастбищ с применением ГИС- и дистанционных технологий, на основе которого выполнена оценка экологического состояния пастбищ для 60 сельских общин. С применением морфологических и морфометрических методов выполнены дифференциация и картографирование пастбищных участков. А оценка их экологического состояния (общая каменистость и степень деградации) проводилась в полевых и камеральных условиях с помощью замеров и визуального дешифрирования космических снимков.

Помимо вышеприведенных основных примеров практического применения ДДЗ в ЦЭНИ имеются базовые научно-технологические ресурсы для развития в перспективе следующих направлений:

1) разработка дешифровочных признаков (прямые и косвенные) загрязнения почв тяжелыми металлами;

2) разработка дистанционных методов оценки энергетического потенциала кормовых угодий;

3) дистанционная диагностика болезней растений и распространения вредителей;

4) разработка дистанционных методов прогнозирования засух.

В заключение можно констатировать, что сочетание наземных и космических данных и междисциплинарный подход исследований обеспечивают надежную научно-методическую 


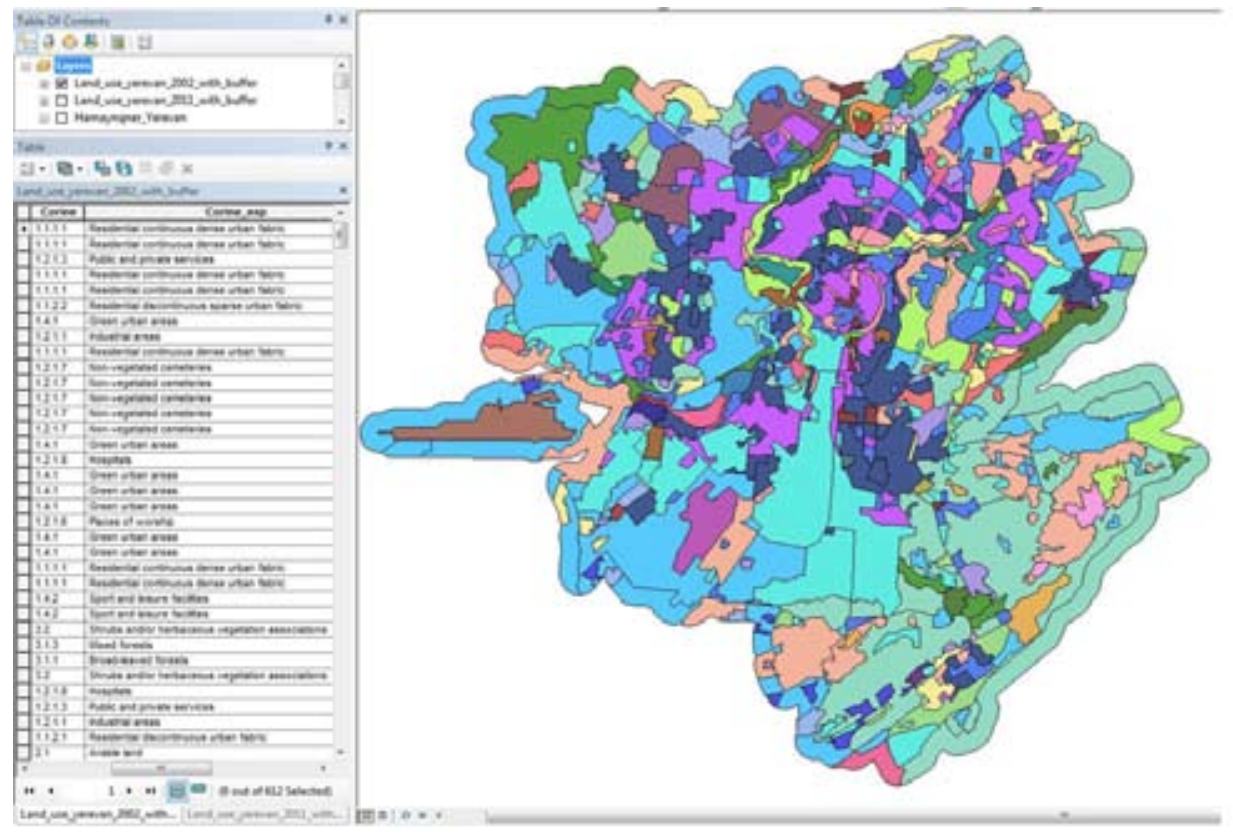

a

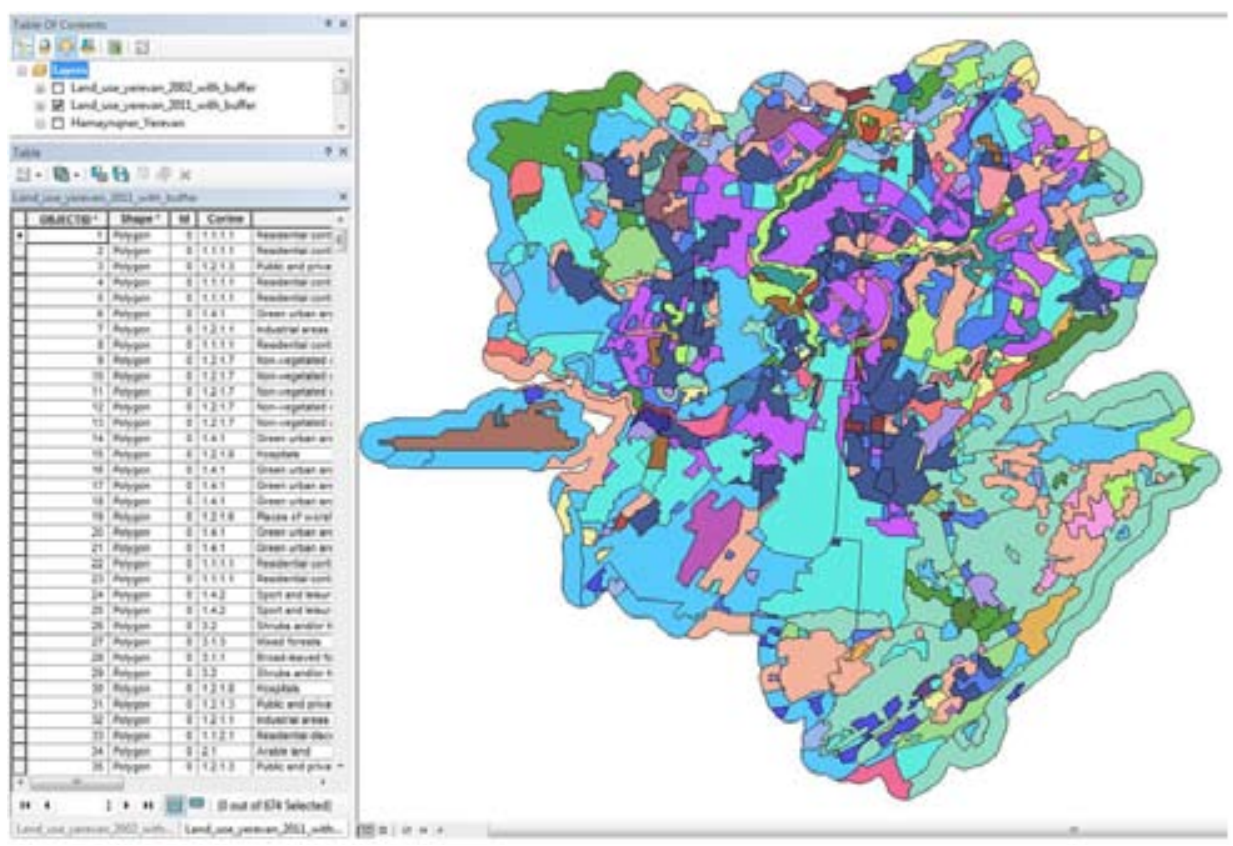

б

Рис. 4. Тематические картографические слои землепользования по номенклатуре CORINE г. Еревана 2002 (а) и 2011 (б) гг.

основу для совершенствования дистанционных методов и создания на этой основе мониторинговой системы с целью поддержки решения проблем территориального управления и вопросов устойчивого развития. 


\section{Список литературы}

[1] Асмарян Ш.Г. Горные территории - экологические проблемы городов: материалы междунар. молодеж. конф. Ереван: Изд-во ЦЭНИ, 2007, 96-100. [Asmarian Sh.G. Mountain areas: urban environmental problems. Erevan, Center for Ecological-Noosphere Studies (CENS), 2007, 96-100].

[2] Асмарян Ш.Г., Мурадян В.С., Бужделев В.В. Агронаука, 2012, 11-12, $752-755$ [Asmarian Sh.G., Muradian V.S., Buzhdelev V.V. Agroscience, 2012, 11-12, 752-755]

[3] Гурьянова Л.В. Вест. Белорус. гос. ун-та. Cер. 2, 2008, 3, 107-112 [Gur'ianova L.V. The Bryansk State University Herald. Ser. 2, 2008, 3, 107-112]

[4] Лурье И.К., Косиков А.Г. Дистанционное зондирование и географические информационные системы; ред. А.М. Берлянт. М.: Научный мир. 2003. 168 c.Lur'e I.K., Kosikov A.G. Distance sensing and geographic information systems, A.M. Berliant (ed.), Moscow, Nauchnyi mir, 2003. 168 p.]

[5] Кронберг П. Дистанциионное изучение земли. М.: Мир, 1988, 352 с. [Kronderg P. Distance Learning of the Earth, Moscow, Mir, 1988. 352 p.]

[6]МакаровВ.З.,НоваковскийБ.А., ЧумаченкоА.Н.Эколого-географическоекартографирование городов. М: Научный мир, 2002, 194 с. [Makarov V.Z., Novakovskii B.A., Chumachenko A.N. Ecological and geographical mapping of the cities. Moscow, Nauchnyi mir, 2002. 194 p.]

[7] Мищенко Н.В., Трифонова Т.А., Карева М.М. // Вестн. МГУ, сер. 17. Почвоведение, 2008, 3, 14-19 [Mishchenko N.V., Trifonova T.A., Kareva M.M. Vestnik MGU [Moscow State University Bulletin], ser. 17. Pochvovedenie, 2008, 3, 14-19]

[8] Николаева Е.А. Известие АН. Серия географическая. 2000, 6, 89-97 [Nikolaeva E.A. Izvestiia RAN. Geografiia [Proceedings of the Academy of Sciences of Russia. Geography], 2000, 6, 89-97]

[9] Трифонова Т.А. Мищенко Н.В. Краснощеков А.Н. Геоинформационные системы и дистанционное зондирование в экологических исследованиях. М: Академический Проект, 2005, 348 c. [Trifonova T.A., Mishchenko N.V., Krasnoshchekov A.N. Geographic information systems and remote sensing for environmental studies. Moscow, Akademicheskii proekt, 2005. 348 p.]

[10] Euyoung Ch., Freek M., Frank R. et. al. J. Remote sensing of environmental, 2008, 112, 32223233.

[11] Giannico C. Acta Astronautica, 2007, 60, 119-131.

[12] Land Use and Land Cover Mapping in Europe. Springer Science+Business Media Dordrecht, 2014. $441 \mathrm{p}$.

[13] Lavalle C., Turchini M., McCormick N. et. al. A flexible methodology for measuring European urban sustainability: the MOLAND Project, 2000.

[14] Shahumyan H., Twumasi B.O., Convery S. et. al. Data Preparation for the MOLAND Model Application for the Greater Dublin Region. UCD Urban Institute Ireland Working Paper Series (0904), 2009, 37 p.

[15] Towards an urban atlas: Assessment of spatial data on 25 European cities and urban areas. Environmental issue report No 30. EEA. Copenhagen, 2002, 128 p.

[16] Late lessons from early warnings: the precautionary principle 1896-200, http://www.eea. europa.eu/publications/environmental_issue_report_2002_3

[17] Y1lmaz R. Springer Science + Business Media B.V. 2009, 603-615. 